\title{
Policy for controlling pain after surgery: effect of sequential changes in management
}

\author{
T H Gould, D L Crosby, M Harmer, S M Lloyd, J N Lunn, G A D Rees, D E Roberts, J A Webster
}

\begin{abstract}
Objective-To observe the effects of introducing an acute pain service to the general surgical wards of a large teaching hospital.

Design-A study in seven stages: (1) an audit of current hospital practice succeeded by the sequential introduction to the general surgical wards of (2) pain assessment charts; (3) an algorithm to allow more frequent use of intramuscular analgesia; (4) increased use of local anaesthetic techniques of wound infiltration and nerve blocks; (5) an information sheet for patients about postoperative pain; (6) the introduction of patient controlled analgesia; (7) a repeat audit of hospital practice. Data were collected on each patient 24 hours after operation.
\end{abstract}

Setting-University Hospital of Wales, which has both district general and tertiary referral functions.

Patients-2035 patients over nine months from all surgical specialties (excluding cardiac) at the hospital. General surgical operations were studied in detail and separated into major, intermediate, and minor for data collection.

Main outcome measures-A change in the median visual analogue pain scores 24 hours after surgery for pain during relaxation, pain on movement, and pain on deep inspiration at each stage of the study.

Results-There was a reduction in median visual analogue scores during the study. The median $(95 \%$ confidence interval) scores for pain during relaxation decreased from 45 (34 to 53) in stage 1 to 16 (10 to 20) in stage 7 for major surgical procedures. Pain on movement decreased from 78 (66 to 80 ) to 46 (38 to 48 , and pain on deep inspiration decreased from 64 (48 to 78 ) to 36 (31 to 38 ). The reductions in median scores for intermediate and minor operative procedures showed similar patterns.

Conclusions-The introduction of an acute pain service to the general surgical wards led to considerable improvement in the level of postoperative pain as assessed by visual analogue scores. Simple techniques of regular pain assessment and the more frequent use of intramuscular analgesia as a result of using an algorithm were particularly effective.

\section{Introduction}

Ready et al first drew attention to the role of an acute pain service in postoperative care of surgical patients. Their study, together with later ones, ${ }^{23}$ placed the emphasis of postoperative pain management regimens on patient controlled analgesia and epidural analgesic infusions. These advanced techniques have obvious benefits for patients. The recommendations of the report by the Royal College of Surgeons of England and College of Anaesthetists outlined a more complete approach to the management of postoperative pain. ${ }^{+}$ Implementing these recommendations should lead to an effective acute pain service to benefit each individual patient after any type of surgical procedure.

The aim of our study was to audit the sequential introduction of an acute pain service to the four general surgical wards and high dependency unit (140 beds) at the University Hospital of Wales and to observe any effect on the management of postoperative pain on the other wards in the hospital. The hospital has 340 surgical beds, which include general, urological, gynaecological, cardiac, neurosurgical, ophthalmic, and ear, nose, and throat surgery.

\section{Subjects and methods}

The study was divided into seven stages during a 42 week period. An initial period of audit of the current hospital practice was succeeded by the sequential introduction of methods of postoperative pain management which were new to the hospital as a whole. The methods introduced at each stage were maintained until completion of the study. The effect of each step was therefore cumulative through the stages of the study. Approval was obtained from the district ethics committee.

The provision of analgesia on the wards was hitherto by intramuscular opioids administered as required every four to six hours. The number of patients who could benefit from patient controlled analgesia, epidural analgesic infusion regimens, or intravenous bolus of opioids was restricted by the established hospital practice to manage these patients on the seven bedded high dependency unit and not on the general wards.

The acute pain team (established for this study) consisted of a research fellow in the department of anaesthetics, who coordinated data collection, and two part time research nurses. The work was supervised by a multidisciplinary team (a consultant surgeon, three consultant anaesthetists, a principal pharmacist, and a senior nursing officer). Monthly meetings of the management group and the three members of the acute pain team were held.

\section{STAGe 1}

The first stage of the study was a six week period of data collection from every surgical patient in the hospital. The existing methods of pain relief and their effects were recorded on a standard questionnaire at a visit 24 hours after operation. The ward nurses were unaware of the reasons for the data collection. The study was concerned thereafter with the practice on general surgical wards and the high dependency unit until the end of stage 6 .

\section{STAGE 2}

The ward nurses were taught to use a simple pain assessment chart with a verbal rating score to assess pain and the level of sedation (fig 1). Respiratory frequency, a sedation score, and a pain assessment score were recorded every two hours for the first 48 hours after operation. Pain was not assessed if the patient was asleep. Observations continued four hourly after the second day. The effects of using the assessment chart were recorded 24 hours after surgery on a standard questionnaire for four weeks. Tutorials were organised for nurses to discuss aspects of pain 


\section{PAIN ASSESSMENT CHART}

Date: $. . . . . / . . . . . / \ldots . . .$.

Ward:

I Respiratory rate: While patient is at rest count respiratory rate for one minute

2 Sedation score: Look at the patient and decide which of the following apply:

Awake

Dozing intermittently

Mostly sleeping

Only awakens when aroused

3 Pain assessment score:

Ask the patient "Which of the following words best describes the pain you are experiencing at the moment":

$\begin{array}{ll}\text { None } & 1 \\ \text { Mild pain } & 2 \\ \text { Moderate pain } & 3 \\ \text { Severe pain } & 4\end{array}$
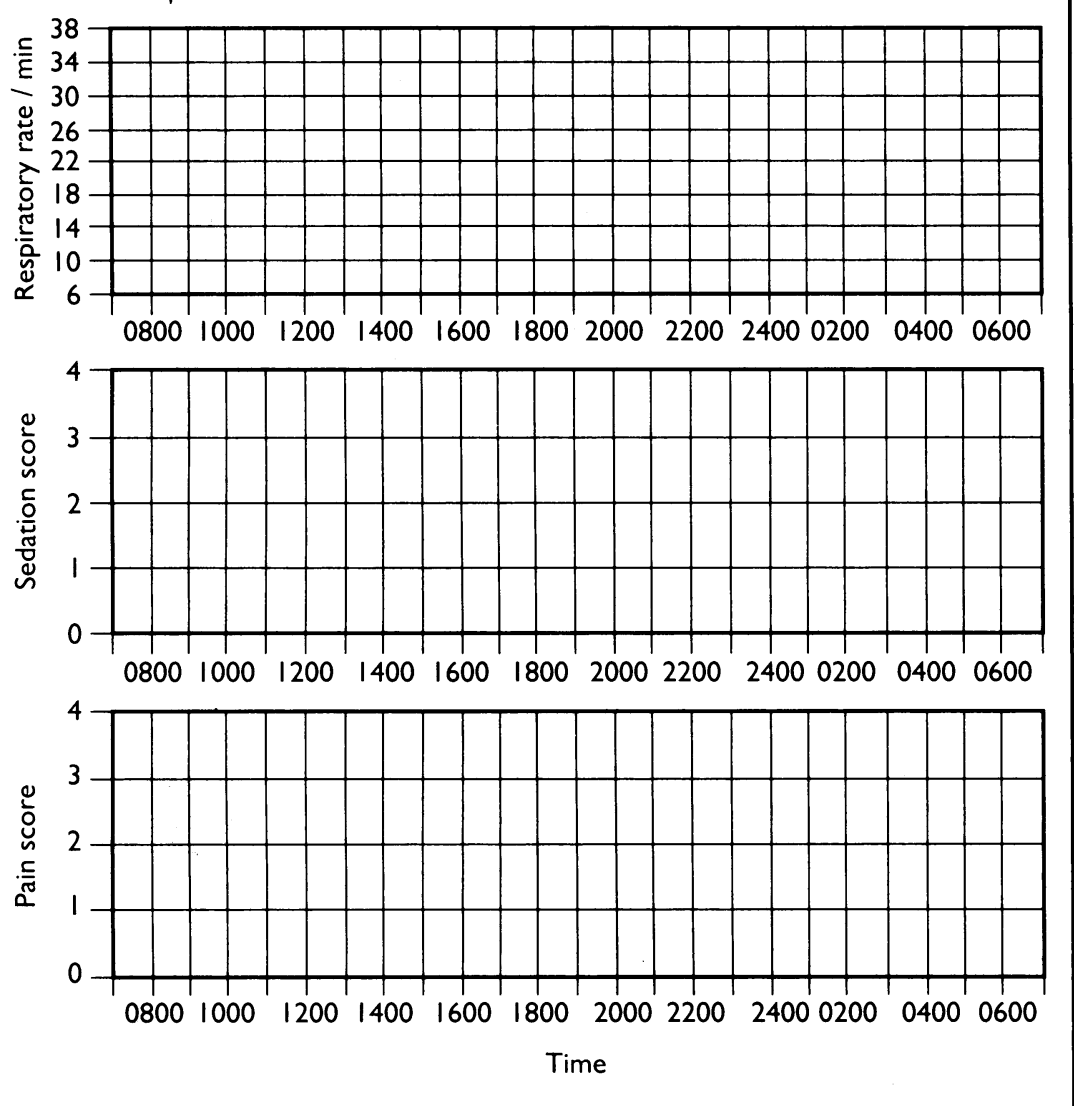

FIG 1-Pain assessment chart

management and a staff nurse from each ward chosen for liaison with the acute pain team.

STAGE 3

An algorithm (fig 2) (similar to one used for subcutaneous infusion regimens by the acute pain service at the Royal Adelaide Hospital, Adelaide, South Australia) was designed to advise the ward nurses when to administer intramuscular opioids. The dose of opioid was prescribed according to the patient's weight (fig 2). The nurses were taught to use the algorithm with information derived from the pain assessment chart. A pain score of 3 or 4 (fig 1 ; moderate or severe pain) allows the patient to be entered at the beginning of the algorithm. A sedation score of 1 or 2 (fig 1), a respiratory frequency of greater than $8 / \mathrm{min}$, and a systolic blood pressure greater than $100 \mathrm{~mm} \mathrm{Hg}$ are requirements before a patient receives further analgesics. A period of more than one hour has also to elapse since the last injection. The effects of using the algorithm were assessed for six weeks.

STAGE 4

Stage 4 was to encourage the general surgeons to use infiltration with local anaesthetic during wound closure and for the anaesthetists to use peripheral nerve blocks when appropriate. The effects of this stage were studied for eight weeks.

STAGE 5

General surgical patients received an information sheet before their operation which gave them details of the different methods of analgesia available and explained that nurses would regularly ask them about pain. The effect of this on pain was assessed for four weeks. This phase of the study was also used to familiarise the general surgical nurses with the use of patient controlled analgesia; this was to be introduced in the next stage.

STAGE 6

Fifteen pumps for patient controlled analgesia were made available for use on the general surgical wards. A protocol was distributed which described the roles of the anaesthetist, the acute pain team, the ward nurses, and the pharmacy in the use of patient controlled analgesia. The types of operations after which patients most likely to benefit from patient controlled analgesia were identified from data collected earlier in the study and a list of these circulated to all anaesthetists (all major and some intermediate surgical procedures; see table I). The patient's anaesthetist decided about the use of patient controlled analgesia and explained the system to the patient before the operation. Pain was controlled in the recovery ward by intravenous bolus doses of morphine before patient controlled analgesia was started. The anaesthetist programmed the pump for a bolus dose of 1 or $2 \mathrm{mg}$ morphine (or $10 \mathrm{mg}$ pethidine) with a lockout of five or 10 minutes.

All patients who used patient controlled analgesia were visited by a member of the acute pain team the night after their operation and then twice a day while they continued to use the pump. A record was kept of the settings of the pump, the total dose of analgesic received, and the levels of sedation. Pain at rest and on movement was assessed with the verbal rating scores (fig 1). Complications, including respiratory depression, were recorded. If the control of pain was inadequate or the sedation levels were inappropriate, then the bolus dose or lockout period was adjusted. Patient controlled analgesia was stopped by the acute pain team when the use by an individual patient became minimal or when the patient could start oral analgesics. Patients using patient controlled analgesia were observed every two hours by the ward nurses and the pain assessment charts (fig 1) completed. The ward nursing staff changed the syringes in the pumps as necessary. There were specific instructions about the management of a decrease in respiratory frequency below 10 breaths/min: the control button for the pump was taken from the patient, oxygen given, and contact made with the acute pain team or the on call anaesthetist. The pharmacy filled syringes with $50 \mathrm{mg}$ morphine $(2 \mathrm{mg} / \mathrm{ml})$. If pethidine was required nurses used ampoules of pethidine $(250 \mathrm{mg}$ in $25 \mathrm{ml}$ made by the pharmacy) to prepare syringes on the wards. This stage lasted eight weeks.

STAGE 7

A repeat survey of all of the surgical wards identical with that in stage 1 was carried out to see if any benefits had spread to wards of the other surgical specialties, which were not involved in stages 2-6 of the study. This 
period of study was six weeks. The duration of each stage of the study was fixed in the study design to try to ensure an equal number of patients at each stage with allowance for holiday periods.

\section{DATA COLLECTION}

A standard questionnaire was used throughout. It was completed 24 hours after surgery for every patient interviewed by one of the three members of the acute pain team. Each questionnaire took about 15 minutes to complete. Details were recorded of the operation type, incision, anaesthetic technique, use of analgesics at any time, and use of antiemetics. Operations in general surgery were grouped to represent major, intermediate, and minor procedures (see table I) according to the expected level of postoperative pain. This classification was by 10 independent anaesthetists, who grouped the potential operations into the three categories before the study.

\section{Guidelines for postoperative intramuscular analgesia}

Every patient receiving intramuscular opioid analgesics must have an intravenous cannula in situ

\begin{tabular}{|cc|}
\hline \multicolumn{2}{|c|}{ Papaveretum } \\
hourly dose intramuscularly \\
Weight $(\mathrm{kg})$ & Dose (mg) \\
$40-65$ & 10 \\
$66-100$ & 15 \\
\hline
\end{tabular}

Papaveretum must not

be used for women

of childbearing age

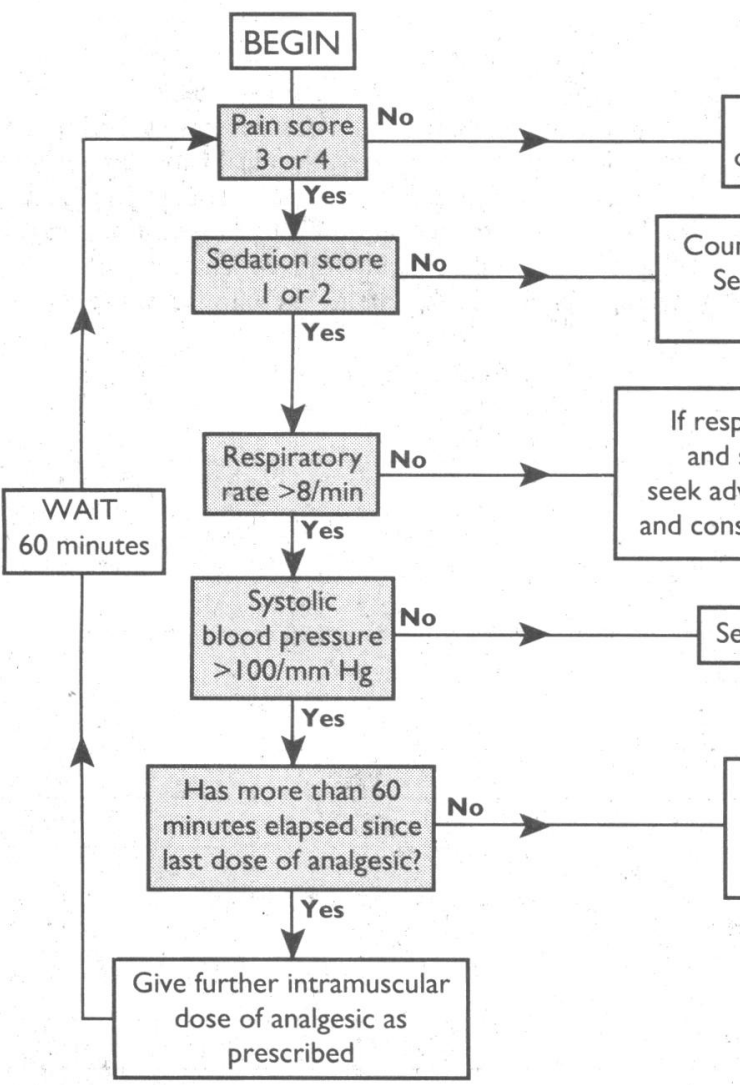

* If pain score 2 and 4-6 hours has elapsed since last intramuscular injection consider oral analgesia.

† Draw up $0.4 \mathrm{mg}(1 \mathrm{ml})$ naloxone $+3 \mathrm{ml}$ isotonic saline and give in $\mathrm{I} \mathrm{ml}$ increments intravenously until respiratory rate $>12 / \mathrm{min}$ and sedation score $<3$.
An assessment of each patient's postoperative pain was made by means of a visual analogue scale. ${ }^{5-8}$ Three visual analogue scores were obtained from each patient for their experience of pain over the previous 24 hours during relaxation in bed, when they moved in bed, and when they took a deep breath. Information was collected about how patients' experience compared with their expectations of postoperative pain, the incidence of delays in receiving analgesia, and the incidence of complications (nausea, vomiting, headache, drowsiness, confusion, or sore throat). Patients who were unable to complete the visual analogue score and all patients who had epidural analgesia were excluded from the study.

\section{STATISTICAL METHODS}

The data collected throughout the study were stored on an Apple Macintosh II computer by using the database programme Foxbase. The data were analysed with the Minitab 8.1 statistical package. Median scores together with $95 \%$ confidence intervals were calculated for each of the three visual analogue pain scores, for each of the three operation groups, for each stage of the study.

The Kruskal-Wallis one way analysis of variance by ranks was used to analyse the median values across the stages for each of the three types of pain assessment in each operation group. This tests the hypothesis that differences among the samples signify genuine population differences between the stages of the study.

The equation given by Siegel and Castellan for multiple comparisons between treatments ${ }^{9}$ was used to identify significant changes in the median values between successive stages of the study. The median score for each stage was compared with the median value of the subsequent stages pooled-that is, stage 1 was compared with the median score for stages 2-7 combined, stage 2 with stages 3-7 combined, and so on until stage 6 was compared with stage 7 . This method avoided comparison of each stage with the single control (stage 1). To test at an $\alpha$ value of $p<0.05$ and $\mathrm{p}<0.01$ with a two tailed test $Z$ values ${ }^{10}$ of 2.64 and 2.87 respectively were used for six comparisons between stages for each visual analogue score.

The differences in median visual analogue scores between stages 1 and 7 for general surgical patients were compared with the differences for three nongeneral surgical operations by using the interaction term in a two factor analysis of variance for non-parametric data. ${ }^{11}$ The three procedureshysterectomies, laparoscopic sterilisations, and nasal operations (polypectomies and antral washouts)-were chosen to represent operations with similar median visual analogue scores in stage 1 to those in the major, intermediate, and minor general surgical operation categories respectively.

\section{Results}

Data were collected from 2035 patients during the seven stages of the study; 1421 were patients on the general surgical wards. Table I shows the different operations in each group. The numbers of cases of each operation are not shown, but there were no significant differences in the number of each operation performed at each stage of the study. Table II shows the different methods of inducing analgesia in use during each stage of the study for the three different categories of general surgery.

In stage 1 data were collected from 213 patients on the general surgical wards and 304 patients from the other surgical specialties. After general surgery intramuscular and oral regimens were used most frequently (table II) and $11 \%$ of patients (24/213) complained of a delay in receiving analgesics. In stage 2 (pain assess- 
TABLE I-Types of operation classified as major, intermediate, and minor procedures

\begin{tabular}{|c|c|c|}
\hline Major procedures & $\begin{array}{l}\text { Intermediate } \\
\text { procedures }\end{array}$ & Minor procedures \\
\hline $\begin{array}{l}\text { Aortic aneurysm } \\
\text { Aortobifemoral } \\
\text { graft } \\
\text { Amputation (lower } \\
\text { limb) } \\
\text { Appendicectomy } \\
\text { Cholecystectomy } \\
\text { Gastrectomy } \\
\text { Incisional hernia } \\
\text { Laparotomy/bowel } \\
\text { resection } \\
\text { Liver/pancreatic } \\
\text { surgery } \\
\text { Splenectomy }\end{array}$ & $\begin{array}{l}\text { Femoral popliteal/ } \\
\text { distal bypass grafting } \\
\text { Haemorrhoidectomy } \\
\text { Inguinal hernia } \\
\text { Laparoscopic } \\
\text { cholecystectomy } \\
\text { Laparoscopic diagnosis } \\
\text { Limb perfusion } \\
\text { Mastectomy } \\
\text { Reconstructive breast } \\
\text { surgery } \\
\text { Skin grafts }\end{array}$ & $\begin{array}{l}\text { Breast lumpectomy } \\
\text { Carotid endarterectomy } \\
\text { Circumcision } \\
\text { Debridement of foot } \\
\text { Examination under } \\
\text { anaesthesia/anal } \\
\text { fissure repair/anal } \\
\text { stretch } \\
\text { Femoral hernia } \\
\text { Paraumbilical hernia } \\
\text { Superficial surgery } \\
\text { Testicular surgery } \\
\text { Thyroidectomy } \\
\text { Varicose veins }\end{array}$ \\
\hline
\end{tabular}

ment charts) fewer patients received no analgesia. The average dose of intramuscular papaveretum in the first 24 hours for patients after major surgery increased from $49 \mathrm{mg}$ (three divided doses) in stage 1 to $64 \mathrm{mg}$ (four divided doses) in stage 2 . The result of stage 3 (the introduction of the algorithm (fig 2 ) in conjunction with the pain assessment chart) was that more patients received analgesics intramuscularly (table II). A reduction occurred in the number of patients who complained of a delay in receiving analgesics from $9 \%$ $(16 / 176)$ in stage 2 to $2 \%(4 / 196)$ in stage 3 . The average dose of papaveretum in the first 24 hours for patients after major surgery did not increase above that in stage 2 , but the average dose frequency increased from four to six doses. These data are not included in the tables because during stage 3 of the study papaveretum (Omnopon) was withdrawn from use in women of childbearing age ${ }^{12}$ and morphine replaced it as the most commonly used analgesic for all patients. The use of morphine on the postoperative wards had previously been minimal and it is not valid to make further comparisons about the changes in dose of intramuscular analgesics.

Our impression was that more patients than shown received wound infiltration in stage 4 (table II) but that its use was not always recorded. The patient information sheet (stage 5) led to a further reduction in the number of patients who received no analgesia and an increase in the use of oral analgesics (table II). The availability of 15 pumps for patient controlled analgesia in stage 6 allowed $71.8 \%$ of patients after major surgery (56/78) to benefit (table II). For patients after a laparotomy the average dose of morphine delivered in the first 24 hours by patient controlled pump was $53 \mathrm{mg}$ compared with $49 \mathrm{mg}$ given intramuscularly in stage 3 . The incidence of nausea with patient controlled analgesia was similar to that in patients given intramuscular analgesics, the incidence of vomiting was less with patient controlled analgesia, and the frequency of use of antiemetics was similar. Patients having patient controlled analgesia were more drowsy during the first 24 hours.

No new treatments were commenced in stage 7 , and the results for the general surgical patients were similar to the results in stage 6 . There were no significant differences in the incidence of complications (nausea, vomiting, headache, drowsiness, confusion, or sore throat) between each of the stages of the study. Patient satisfaction improved through the study. In stage 1 , $34 \%$ of patients $(72 / 213)$ complained that their pain was worse or much worse than they had expected. By stage 7 only $12 \%$ of patients $(26 / 219)$ complained of this. By stage $7,67 \%$ of patients $(147 / 219)$ said that their pain was better than expected; in stage $142 \%$ of patients $(90 / 213)$ said this.

\section{VISUAL ANALOGUE SCORES}

The median scores and $95 \%$ confidence intervals of the median scores for the three types of visual analogue scale for major, intermediate, and minor surgical procedures for each stage of the study are shown in figure 3. For each procedure figure 3 also shows the results of the Kruskal-Wallis analysis of variance by rank for the median scores of the seven stages.

\section{Major surgical procedures}

Analysis of the median visual analogue scores for pain during relaxation, pain on movement, and pain on deep inspiration after major surgical procedures (fig 3) indicated that the differences between the median values for the seven stages of the study did not arise by chance but could not identify which step change was important. In figure 3 the median scores presented

TABLE II-Numbers (percentages) of patients receiving different methods of analgesia for major, intermediate, and minor surgical procedures

\begin{tabular}{|c|c|c|c|c|c|c|c|}
\hline \multirow[b]{2}{*}{$\begin{array}{l}\text { Type of postoperative } \\
\text { analgesia }\end{array}$} & \multicolumn{7}{|c|}{ Sequence of stages of study } \\
\hline & $\begin{array}{c}1 \\
\text { (control group) }\end{array}$ & $\begin{array}{c}2 \\
\text { (pain chart) }\end{array}$ & $\begin{array}{c}3 \\
\text { (algorithm) }\end{array}$ & $\begin{array}{c}4 \\
\text { (local } \\
\text { anaesthetic) }\end{array}$ & $\begin{array}{c}5 \\
\text { (patient letter) }\end{array}$ & $\begin{array}{c}6 \\
\text { (patient } \\
\text { controlled } \\
\text { analgesia) }\end{array}$ & $\begin{array}{c}7 \\
\text { (final survey) }\end{array}$ \\
\hline Total No of cases: & 213 & 176 & 196 & 229 & 152 & 236 & 219 \\
\hline $\begin{array}{l}\text { Intramuscular } \\
\text { Intravenous bolus } \\
\text { Patient controlled analgesia }\end{array}$ & $\begin{array}{r}27(62 \cdot 8) \\
11(25 \cdot 6) \\
5(11 \cdot 6)\end{array}$ & $\begin{array}{l}38(64 \cdot 4) \\
11(18 \cdot 6) \\
10(17 \cdot 0) \\
\end{array}$ & $\begin{array}{l}\text { Major procedu } \\
46(76 \cdot 6) \\
7(11 \cdot 7) \\
7(11 \cdot 7) \\
\end{array}$ & $\begin{array}{c}36(73 \cdot 4) \\
3(6 \cdot 2) \\
10(20 \cdot 4) \\
\end{array}$ & $\begin{array}{r}24(68 \cdot 7) \\
5(14 \cdot 2) \\
6(17 \cdot 1) \\
\end{array}$ & $\begin{array}{l}21(27 \cdot 0) \\
1(1 \cdot 2) \\
56(71 \cdot 8) \\
\end{array}$ & $\begin{array}{l}19(26 \cdot 7) \\
0 \\
52(73 \cdot 3)\end{array}$ \\
\hline Total & $43(100)$ & $59(100)$ & $60(100)$ & $49(100)$ & $35(100)$ & $78(100)$ & $71(100)$ \\
\hline Local anaesthetic used & 0 & $3(5 \cdot 0)$ & $5(8 \cdot 3)$ & $25(51 \cdot 0)$ & $19(54 \cdot 3)$ & $27(34 \cdot 6)$ & $24(33 \cdot 8)$ \\
\hline \multicolumn{8}{|c|}{ Intermediate procedures } \\
\hline $\begin{array}{l}\text { Intramuscular } \\
\text { Oral } \\
\text { Intravenous bolus } \\
\text { Patient controlled analgesia } \\
\text { No analgesia } \\
\end{array}$ & $\begin{array}{c}59(63 \cdot 5) \\
19(20 \cdot 5) \\
2(2 \cdot 0) \\
0 \\
13(14 \cdot 0) \\
\end{array}$ & $\begin{array}{l}43(63 \cdot 2) \\
16(23 \cdot 5) \\
2(3 \cdot 0) \\
0 \\
7(10 \cdot 3) \\
\end{array}$ & $\begin{array}{c}61(71 \cdot 0) \\
10(11 \cdot 6) \\
5(5 \cdot 8) \\
4(4 \cdot 6) \\
6(7 \cdot 0) \\
\end{array}$ & $\begin{array}{l}69(68 \cdot 4) \\
16(15 \cdot 8) \\
6(5 \cdot 9) \\
0 \\
10(9 \cdot 9) \\
\end{array}$ & $\begin{array}{l}38(68 \cdot 0) \\
13(23 \cdot 2) \\
3(5 \cdot 3) \\
0 \\
2(3 \cdot 5) \\
\end{array}$ & $\begin{array}{c}62(64 \cdot 6) \\
17(17 \cdot 7) \\
2(2 \cdot 1) \\
11(11 \cdot 5) \\
4(4 \cdot 1) \\
\end{array}$ & $\begin{array}{c}49(62 \cdot 9) \\
14(17 \cdot 8) \\
1(1 \cdot 3) \\
11(14 \cdot 1) \\
3(3 \cdot 9) \\
\end{array}$ \\
\hline Total & $93(100)$ & $68(100)$ & $86(100)$ & $101(100)$ & $56(100)$ & $96(100)$ & $78(100)$ \\
\hline Local anaesthesic used & $7(7 \cdot 5)$ & $8(11 \cdot 7)$ & $13(15 \cdot 1)$ & $52(51 \cdot 5)$ & $32(57 \cdot 1)$ & $46(47 \cdot 9)$ & $33(42 \cdot 3)$ \\
\hline \multicolumn{8}{|c|}{ Minor procedures } \\
\hline $\begin{array}{l}\text { Intramuscular } \\
\text { Oral } \\
\text { No analgesia }\end{array}$ & $\begin{array}{l}33(42 \cdot 9) \\
27(35 \cdot 0) \\
17(22 \cdot 1)\end{array}$ & $\begin{array}{r}22(44 \cdot 9) \\
19(38 \cdot 7) \\
8(16 \cdot 4)\end{array}$ & $\begin{array}{r}26(52 \cdot 0) \\
15(30 \cdot 0) \\
9(18 \cdot 0) \\
\end{array}$ & $\begin{array}{l}34(43 \cdot 0) \\
28(35 \cdot 4) \\
17(21 \cdot 6)\end{array}$ & $\begin{array}{r}24(39 \cdot 4) \\
29(47 \cdot 5) \\
8(13 \cdot 1) \\
\end{array}$ & $\begin{array}{l}24(38 \cdot 7) \\
28(45 \cdot 2) \\
10(16 \cdot 1)\end{array}$ & $\begin{array}{l}26(37 \cdot 2) \\
33(47 \cdot 1) \\
11(15 \cdot 7)\end{array}$ \\
\hline Total & $77(100)$ & $49(100)$ & $50(100)$ & $79(100)$ & $61(100)$ & $62(100)$ & $70(100)$ \\
\hline Local anaesthetic used & $2(2 \cdot 6)$ & $1(2 \cdot 0)$ & $4(8 \cdot 0)$ & $21(26 \cdot 5)$ & $14(22.9)$ & $12(19 \cdot 3)$ & $14(20 \cdot 0)$ \\
\hline
\end{tabular}


Major surgical procedures

O Pain during relaxation

Kruskal-Wallis $\mathrm{H}=50.43, \mathrm{p}<0.0001$

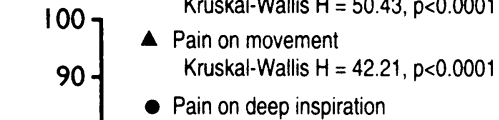

- Pain on deep inspiration

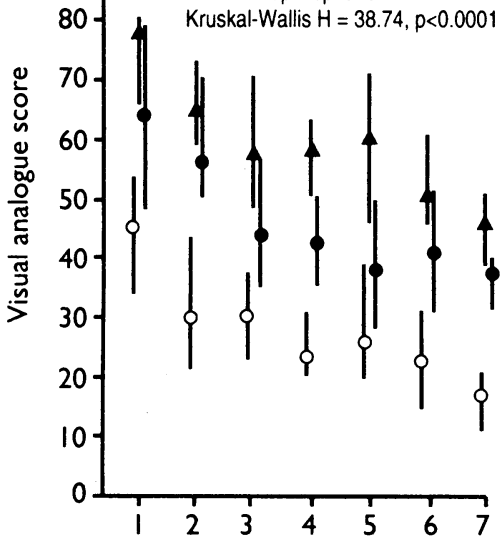

Intermediate surgical procedures

o Pain during relaxation

Kruskal-Wallis $\mathrm{H}=24.79, \mathrm{p}<0.0001$

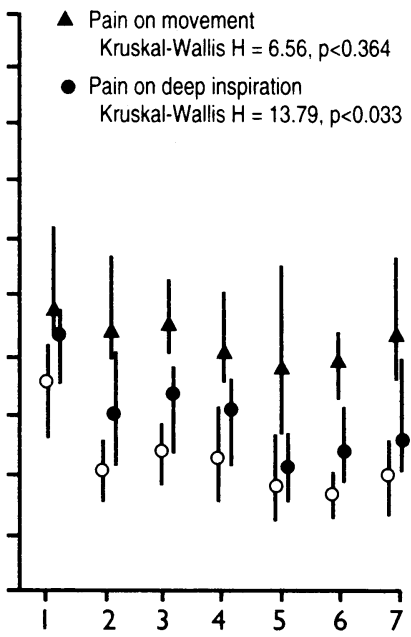

Minor surgical procedures

- Pain during relaxation Kruskal-Wallis $\mathrm{H}=25.05, \mathrm{p}<0.000$

$\Delta$ Pain on movement Kruskal-Wallis $\mathrm{H}=21.64, \mathrm{p}<0.002$

- Pain on deep inspiration Kruskal-Wallis $\mathrm{H}=22.53, \mathrm{p}<0.001$

Sequence of stages in study

FIG 3-Median visual analogue scores and 95\% confidence intervals for pain during relaxation, pain on movement, and pain on deep inspiration after major, intermediate, and minor surgical procedures

together with the $95 \%$ confidence intervals show that there was a reduction in median value through the study. An impression can be gained about the reduction in median scores by examining the extent of overlap of the confidence interval in stage 1 with the intervals at stages 4-7 for each visual analogue assessment. Certainly by these stages of the study a significant reduction in median pain scores seems to have occurred. It was inappropriate to apply MannWhitney $U$ tests to the changes in the median values because with so many comparisons between medians some of the $\mathrm{p}$ values may have been significant by chance.

We wanted to determine the stage of the study beyond which no further significant decrease in median value occurred. The median value for each stage was compared with the median value of the subsequent stages combined by using the multiple comparisons procedure described above. Table III shows solely the significant differences in median pain scores. Improvements between successive stages that were significant ceased after stage 3 for all types of pain measurement.

TABLE III-Comparison between visual analogue scores for pain during relaxation, pain on movement, and pain on deep inspiration for major, intermediate, and minor surgical procedures. (Significant results only)

\begin{tabular}{|c|c|c|c|}
\hline \multirow[b]{2}{*}{ Comparison of stages } & \multicolumn{2}{|c|}{$\begin{array}{l}\text { Median visual analogue score } \\
(95 \% \text { confidence interval })\end{array}$} & \multirow[b]{2}{*}{ Significance } \\
\hline & Index stage ${ }^{\star}$ & Subsequent stages & \\
\hline . & \multicolumn{2}{|l|}{ Major procedures } & \\
\hline \multicolumn{4}{|l|}{ Pain during relaxation: } \\
\hline Stage 1 with subsequent stages & 45 (34 to 53$)$ & 23 (20 to 26 ) & $\mathrm{p}<0.01$ \\
\hline Stage 2 with subsequent stages & 30 (21 to 43 ) & 22 (20 to 24$)$ & $\mathrm{p}<0.05$ \\
\hline \multicolumn{4}{|l|}{ Pain on movement: } \\
\hline Stage 1 with subsequent stages & $78(66$ to 80$)$ & $54 \cdot 5(50$ to 58$)$ & $\mathrm{p}<0.01$ \\
\hline Stage 2 with subsequent stages & $65(59$ to 73$)$ & $50(48$ to 55$)$ & $\mathrm{p}<0.01$ \\
\hline \multicolumn{4}{|l|}{ Pain on deep inspiration: } \\
\hline Stage 1 with subsequent stages & 64 (48 to 79$)$ & $42(38$ to 45$)$ & $\mathrm{p}<0.01$ \\
\hline Stage 2 with subsequent stages & $56(50$ to 70$)$ & 38 ( 36 to 42 ) & $\mathrm{p}<0.01$ \\
\hline \multicolumn{4}{|c|}{ Intermediate procedures } \\
\hline \multicolumn{4}{|l|}{ Pain during relaxation: } \\
\hline \multirow{2}{*}{\multicolumn{4}{|c|}{ Pain on deep inspiration: }} \\
\hline & & & \\
\hline \multirow[t]{2}{*}{ Stage 1 with subsequent stages } & 43 (35 to 47 ) & 26 (23 to 30$)$ & $\mathrm{p}<0.01$ \\
\hline & Minor procedures & & \\
\hline \multicolumn{4}{|l|}{ Pain during relaxation: } \\
\hline Stage 1 with subsequent stages & 21 (11 to 32$)$ & $14(11$ to 16$)$ & $\mathrm{p}<0.05$ \\
\hline Stage 2 with subsequent stages & 22 (19 to 29$)$ & $11.5(9$ to 15$)$ & $p<0.05$ \\
\hline \multicolumn{4}{|l|}{ Pain on movement: } \\
\hline Stage 1 with subsequent stages & 39 (32 to 45$)$ & $27(22$ to 30$)$ & $\mathrm{p}<0.01$ \\
\hline Stage 2 with subsequent stages & $36(32$ to 40$)$ & 23.5 (19 to 27$)$ & $\mathrm{p}<0.01$ \\
\hline \multicolumn{4}{|l|}{ Pain on deep inspiration: } \\
\hline Stage 1 with subsequent stages & 25 (12 to 34$)$ & $15(12$ to 18$)$ & $\mathrm{p}<0.01$ \\
\hline Stage 2 with subsequent stages & 25 (18 to 31$)$ & $14(10$ to 16$)$ & $\mathrm{p}<0.01$ \\
\hline
\end{tabular}

^Index stage represents stage with which other stages are compared.
Intermediate surgical procedures

After intermediate surgical procedures the differences between the median visual analogue scores for pain during relaxation and pain on deep inspiration were significant, but the differences for pain on movement were not (fig 3 ). The reductions in median scores were more limited than those in operation group 1. Table III shows that a significant change occurred between stage 1 and all subsequent stages combined for pain during relaxation $(p<0.01)$ and for pain on deep inspiration $(\mathrm{p}<0.01)$.

\section{Minor surgical procedures}

The changes in median visual analogue scores were significant for all three types of pain after minor procedures, although they were less than those in operation group 1. There was a significant change in the median values between stage 1 and stage 2 when compared with all subsequent stages. The stepwise changes after stage 3 were not significant.

\section{Pain after other types of surgery}

The results for 304 patients from the other nongeneral surgical specialties in stage 1 were compared with those for the 310 patients from stage 7 . The number and mix of operations were similar in the two stages. The percentage of patients who complained that their pain was worse or much worse than expected was similar in the two stages. There were, however, differences in the visual analogue scores between the two stages for some operations (table IV).

The results of the two factor analysis of variance compared the difference for the visual analogue pain scores between stage 1 and stage 7 for the three nongeneral surgical operations and the three operation categories for general surgery (table IV). There were no significant $p$ values. This indicates that the pattern of changes on the non-general surgical wards for the three operations was similar to the pattern of changes that occurred on the general surgical wards.

The two factor analysis of variance used may not have been powerful enough to detect significant differences for the comparisons that were made. For example, in table IV under intermediate surgery and laparoscopic sterilisation the reduction in median values between stage 1 and stage 7 for pain on deep inspiration was 18 (43-25) for the intermediate surgery group compared with $2(31-29)$ for the laparoscopic sterilisation group, yet the $\mathrm{p}$ value is 0.75 . 
TABLE IV-Comparison of stages 1 and 7 with respect to major surgical procedures and hysterectomy, intermediate surgical procedures and laparoscopic sterilisation, and minor surgical procedures and nasal operations

$\mathrm{p}$ Value for

Median visual interactive No of patients analogue score two way No of patients analogue score two ways of

Comparison of stages Stage 1 Stage 7 Stage 1 Stage 7 variance*

Major procedures and hysterectomy

Pain during relaxation:

Major procedures

Hysterectomy

Pain on movement:

Major procedures

Hysterectomy

Pain on deep inspiration:

Major procedures

Hysterectomy

Intermediat

Pain during relaxation:

$\begin{array}{llllll}\text { Intermediate procedures } & 93 & 78 & 35 & 19 & \mathrm{p}=0.29 \\ \text { Laparoscopic sterilisation } & 30 & 28 & 25 & 20 & \end{array}$

Laparoscopic sterilisation

43
29

$\begin{array}{ll}71 & 45 \\ 38 & 59\end{array}$

$\begin{array}{ll}45 & 16 \\ 59 & 31 \cdot 5\end{array}$

$1 \cdot 5 \quad p=0 \cdot 17$

$43 \quad 71$

78
83

$\begin{array}{ll}78 & 46 \\ 83 & 34\end{array}$

$\mathrm{p}=0 \cdot 2$

$\begin{array}{lllll}43 & 71 & 64 & 36 & \mathrm{p}=0.39\end{array}$

Pain on movement:

Intermediate procedures

Laparoscopic sterilisation

Pain on deep inspiration:

Intermediate procedures

Laparoscopic sterilisation

Pain during relaxation:

Minor procedure

Nasal surgery

Pain on movement:

Minor procedures

Pain on deep inspiration

Minor procedures

Minor procedures
Nasal surgery

Minor procedures and nasal surgery

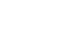

$\mathrm{p}=0.85$

$p=0 \cdot 75$

$\begin{array}{lll}77 & 70 & 21\end{array}$

$\begin{array}{lllcl}77 & 70 & 21 & 10.5 & \mathrm{p}=0.74\end{array}$

$\begin{array}{lllll}77 & 70 & 39 & 20 \cdot 5\end{array}$

$26 \quad 29$

$39 \quad 20 \cdot 5$

$p=0.93$

$\begin{array}{rrrrr}77 & 70 & 25 & 13 & \mathrm{p}=0 \cdot 37\end{array}$

*Interpretation of $\mathrm{p}$ values explained in Results.

\section{Discussion}

The stages of our study followed the recommendations of the report of the working party of the Royal College of Surgeons of England and College of Anaesthetists on pain after surgery. ${ }^{+}$The emphasis was on the development of an acute pain service with a policy for pain relief after surgery which would benefit every patient after any type of operation. The results of the study help to show which treatment strategies are of most benefit for different general surgical procedures.

One of the recommendations of the above report was the systematic assessment of postoperative pain; this was an early part of the study. Pain is subjective and therefore difficult to measure, and an attempt to quantify it is important; but which methods are suitable? The McGill questionnaire ${ }^{13}$ uses a multidimensional approach to assess pain but is too complicated in the immediate postoperative period. A retrospective visual analogue score at 24 hours is widely used and validated ${ }^{14}$ and is suitable for data collection from the large number of patients as in our study. Some patients do not understand the visual analogue scale and a numerical rating scale may be easier. Both may be impractical in the very early postoperative period.

Assessment must be regular if management of postoperative pain for individual patients is to be improved. A verbal rating score (fig 1 ) is particularly easy for the nursing staff to use and for patients to understand. The progress of an individual patient can be clearly seen if each pain score is charted on a graph and not just recorded as a number. To this end pain assessment charts should ultimately be included in the routine postoperative observation chart. ${ }^{15}$ The assessment of pain at rest is probably of dubious value ${ }^{16}$ as our results show; a reduction in pain during relaxation is easy to achieve whereas pain on movement and pain on deep inspiration are more discriminative of analgesic efficacy.

Staff education about postoperative pain during the study was through small tutorial groups of nursing and medical staff, which provided a forum for the discussion of problems and misconceptions as well as time for formal teaching. Student nurses are now formally taught during their training at the University Hospital of Wales by members of the acute pain team. Similar arrangements for undergraduate medical staff are being explored. Education of health care professionals about postoperative pain need not cost any more money if those who teach change attitudes, convey new ideas, and give adequate priority to the subject.

The algorithm was used in 559 patients who required intramuscular analgesia from stage 3 until the end of the study. Intramuscular analgesia was available hourly as required but patients only received it as frequently as this when they first returned to the ward. Patients then required analgesia every two to three hours. The algorithm gave the nurses flexibility to administer analgesics when necessary. Most patients did not complain about the frequency of injections, but an indwelling subcutaneous or intramuscular catheter could be used for morphine to avoid repeat injections. The variable uptake from a single site may make this method unsuitable for pethidine. ${ }^{17}$ The safety of the algorithm relies on the regular assessment of the patients by means of the pain assessment chart. Three patients had episodes of a respiratory frequency of less than $8 \mathrm{~min}$. These required attention from a member of the team and naloxone because the patients also had high sedation scores. None had received analgesia on the wards as a result of the algorithm. Respiratory depression was detected by using a pain assessment chart and occurred as a result of large doses of morphine given during and immediately after the operation.

The nurses on the wards had no problems in quickly learning to use the pain assessment charts; however, the algorithm took about two weeks to introduce effectively. The initial resistance to the frequent assessment and injections was overcome once the benefit for individual patients was observed by the nurses on the wards.

The use of a visual analogue score at 24 hours may not have been sensitive enough to detect the early benefit of wound infiltration since no further significant fall in overall visual analogue scores occurred below those in stage 3 . However, a reduction of over $50 \%$ for each visual analogue score was seen in patients after mastectomy and inguinal herniorrhaphy when local anaesthetic wound infiltration was used. Obviously there is a place for local anaesthetic infiltration in some procedures, but more work is needed to ascertain which layers of the wound need to be infiltrated. Infusions of local anaesthetics in the wound could have a place and are already used for some nerve blocks..$^{18}$ In our study local anaesthetic preparations were included by the theatre nurses on instrument trays and offered to the surgeons during wound closure. There was minimal increase in surgical time from this procedure. The local anaesthetic nerve blocks when used before surgery were simple and increased anaesthetic time by about five minutes. We think any delays as a result of these techniques are outweighed by the benefits to patients.

Preoperative patient education about postoperative pain caused no detectable change in visual analogue scores but did increase the number of patients who received analgesics (table II). Improved understanding by the patient must be part of the overall strategy for any acute pain team.

\section{PATIENT CONTROLLED ANALGESIA}

The introduction of patient controlled analgesia had no significant effect on the pain scores already achieved by stage 5 . There is a point as a result of the study design at which it is less easy to detect a reduction in 
median scores with each subsequent stage because of the improvements that have already taken place. The median visual analogue score by stage 6 for pain during relaxation after major surgical procedures is very acceptable, but scores for pain on movement and pain on deep inspiration are still too high for us to be complacent. Patient controlled analgesia offers a quick response by the patient to pain, allows anticipation of pain on movement, and has proved its value in other studies,${ }^{1920}$ but to reduce these scores further it may be necessary to use epidural infusion regimens. In stage 6 more patients said their pain was better than expected compared with previous stages. The increased use of patient controlled analgesia in patients after hysterectomy in stage 7 (nine out of 38 patients) compared with stage 1 (none out of 29 patients) partly accounted for the fall in visual analogue scores in this group of patients. The use of patient controlled analgesia in these patients was outside the control of the acute pain team.

Our experience of 130 patients using patient controlled analgesia during the study and a further 380 since the study finished suggests that an initial regimen of morphine $1 \mathrm{mg}$ bolus with a five minute lockout is optimum for all patients, provided it is regularly assessed and adjusted when necessary. We think there is a place for a default setting of the above regimen as new patient controlled analgesia machines become more complicated. The programme on a patient controlled analgesia pump could be greatly simplified to facilitate ease of operation by nursing and medical staff. We chose not to use a background infusion or to set a four hour limit, which are two of the current programme options on most patient controlled analgesia pumps. A background infusion in combination with patient controlled analgesia may cause respiratory depression, ${ }^{21}$ and a four hour limit is against the principle of patient controlled analgesia but could alert medical staff to those patients who require more analgesia than is available.

The study showed some spread of ideas to nongeneral surgical wards as recorded in stage 7 . There were changes in ward practice which may account for the reductions in median visual analogue scores (table IV) for the three selected surgical procedures. Patients after hysterectomy were prescribed larger doses of opioids in stage 7 than in stage 1 , and $24 \%$ received patient controlled analgesia compared with none in stage 1. There was some movement of doctors and nurses from wards in the study to the other wards and probably an increase in the level of awareness of postoperative pain among doctors and nurses generally, which may also have contributed to these changes. This can be interpreted as a beneficial effect in the remainder of the hospital.

The key features in our acute pain service were a multidisciplinary team working together to solve administrative problems and to decide protocols; the regular presence of members of the team on the wards ensures that an expert is readily available to teach and to audit standards; the enthusiasm of the members of the acute pain team and cooperation of the ward nurses, who now refuse to return to the previous methods of management of postoperative pain.

There are capital and revenue cost implications in an acute pain team. The optimum may be access to patient controlled analgesia or epidural regimens, but we have shown clearly the benefits achieved by simple methods of pain assessment and the optimal use of intramuscular analgesia for patients after surgery.

\section{POSTSCRIPT}

The hospital manager has decided to finance the acute pain team. The methods used on the general surgical wards are now in use on most of the other surgical wards. The next phase of our work is to introduce epidural regimens to the general surgical wards, since this was not possible within the time limits of the study.

The study was entirely supported by a grant from the National Hospital Trust to the University Hospital of Wales. We are grateful for the opportunity which this afforded us to study this matter in a systematic manner. We thank Professor W W Mapleson, department of anaesthetics, and Dr T J Peters, department of medical computing and statistics in the University of Wales College of Medicine, for their advice with the statistical methods used in this study.

1 Ready BL, Oden R, Chadwick HS, Bendetti C, Rooke A, Caplan R, et al. Development of an anesthesiology based postoperative pain management service. Anesthesiology 1988;68:100-6.

2 Macintyre PE, Runciman WB, Webb RK. An acute pain service in an Australian teaching hospital: the first year. Med f Aust 1990;1 153:417-21.

3 Wheatley RG, Madej TH, Jackson IJB, Hunter D. The first year's experience of an acute pain service. Br f Anaesth 1991;67:353-9.

4 Royal College of Surgeons of England, College of Anaesthetists. Commission on the provision of surgical services. Report of the working party on pain after surgery. London: Royal College of Surgeons, 1990 .

5 Revill SI, Robinson JO, Rosen M, Hogg MIJ. The reliability of a linear analogue for evaluating pain. Anaesthesia 1976;31:1191-8.

6 White WD, Pearce DJ, Norman J. Postoperative analgesia, a comparison of intravenous on demand fentanyl with epidural bupivacaine. BMF 1979;ii: intraven.

7 Fell D, Chmielewski A, Smith G. Postoperative analgesia with controlledrelease morphine sulphate: comparison with intramuscular morphine. $B M J$ 1982;285:92-4.

8 Banos JE, Bosch F, Canellas M, Bassols A, Ortega F, Bigorra J. Acceptability of visual analogue scales in the clinical setting: a comparison with verbal rating scales in postoperative pain. Methods Find Exp Clin Pharmacol 1989;11:123-7.

9 Siegel S, Castellan NJ. Nonparametric statistics for the behavioral sciences. 2nd ed. New York: McGraw Hill, 1988:213.

10 Siegel S, Castellan NJ. Nonparametric statistics for the behavioral sciences. 2nd ed. New York: McGraw Hill, 1988:table Aii.

$11 \mathrm{Zar}$ JH. Biostatistical analysis. 2nd ed. New Jersey: Prentice-Hall, 1984:sect $13.4(219-22)$.

12 Committee on Safety of Medicines. Genotoxicity of papaveretum and noscapine. Current Problems 1991;31:3-4.

13 Melzak R. The McGill pain questionnaire: major properties and scoring methods. Pain 1975;1:275-99.

14 Liu WH, Aitkenhead AR. Comparison of contemporaneous and retrospective assessment of postoperative pain using visual analogue scale. $\mathrm{Br}$ f Anaesth $1991 ; 67: 768-71$

15 Smith G. Postoperative pain. In: Lunn JN, ed. Quality of care in anaesthetic practice. London: Macmillan, 1984:164-79.

16 Bahar M, Rosen M, Vickers MD. Self administered nalbuphine, morphine and pethidine; comparison, by intravenous route, following cholecystectomy. Anaesthesia 1985;40:529-32.

17 Mather LE, Lindop MJ, Tucker GT, Pflug AE. Pethidine revisited: plasma concentrations and effects after intramuscular injection. $\mathrm{Br} \mathcal{F}$ Anaesth 1975;47:1269.

18 Lee A, Boon D, Bagshaw P, Kempthorne P. A randomised double-blind study of intrapleural analgesia after cholecystectomy. Anaesthesia 1990;46: 1028-31

19 Magnani B, Johnson LR. Patient controlled analgesia for the control of postoperative pain. In: Ferrante FM, Ostheimer GW, Covino BG, eds. Patient controlled analgesia. Boston: Blackwell Scientific, 1990:85-101.

20 Lehmann KA, White PF, Bennett RL. Practical experience. In: Harmer M, Rosen M, Vickers MD, eds. Patient controlled analgesia. London: Blackwell Scientific, 1985:134-55.

21 Owen H, Szekely SM, Plummer JL, Cushnie JM, Mather LE. Variables of patient controlled analgesia 2. Concurrent infusion. Anaesthesia 1989;44: $11-3$.

(Accepted 9 September 1992) 